\title{
Becoming Dead: Burial Assemblages as Vitalist Devices
}

\author{
Fredrik Fahlander
}

This text comprises a critical discussion of assemblage theory and its application to burial studies. In recent research, burials have been viewed as fluid and indeterminate assemblages that 'become' in varied ways depending on different perceptions (concepts and ideas) and apparatuses (e.g. excavation tools and measuring instruments). The past and the present are thus mixed in potentially ever-new configurations which run the risk of replacing epistemological relativism with ontological fluidity. It is argued here that the hypothetical mutability of burial assemblages can be reduced significantly by addressing the varying speed and degree of the involved processes of integration and disintegration. $B y$ doing this, the main focus is shifted to the animacy of such processes and how they may have been understood and utilized in burials. Using both general and specific examples, it is argued that cremation burials can be studied as carefully compiled amalgamations that utilize the properties and animacies of different materialities to deal with death, corpses and the afterlife.

\section{Introduction}

As a field of research, burial archaeology has seen several rapid theoretical and methodological advances during the new millennium. The interest in ontology and materiality, in particular, has widened the focus in burial archaeology from questions of social identity and structure to challenge our most basic assumptions of identity, personhood, death and burial (e.g. Cummings 2012; Fahlander 2018a; Fowler 2013). On a general level, the apparent care invested in prehistoric burials is easy to empathize with and resonates with our own ways of burying the dead. In contemporary Western societies, graves are generally perceived as resting places for an individual, while in other ontologies, the deposition of dead bodies may be performed with quite different aims and purposes (Huntington \& Metcalf 1991). Prehistoric graves are often complex features containing a broad range of amalgamated materialities and arrangements that are not always related to the age, sex and status of the deceased individual. For instance, some graves include more than one person, while other grave-like features do not include any bodies at all. In some cases, animals and artefacts are disposed of in a similar way to human bodies (Morey 2006). There are also frequent examples of re-opened and manipulated graves where things have been added or removed on a later occasion (see Gardela \& Kajkowski 2015, with references). This suggests that not all burials are mere resting places for a dead body, but are perhaps better understood as contraptions designed to deal with death, corpses and inalienable things. From such a perspective, some graves have been designed to disarm or contain the agency of the dead, while others aim to enhance and reinforce it. Looking at burials in this way also suggests that seemingly obvious interments can be reinterpreted based on what they do rather than what they represent or symbolize.

A similar focus on such generative aspects of burials has recently been explored within assemblage theory (Fahlander 2014; Fowler 2013; Fowler \& Harris 2015; Jervis 2019; Jones 2012; van Vliet 2015). In these studies, graves are not perceived as passive 'closed finds', but as gatherings of materialities with no clear demarcation in time and space.

Cambridge Archaeological Journal 30:4, 555-569 ( 2020 McDonald Institute for Archaeological Research. This is an Open Access article, distributed under the terms of the Creative Commons Attribution licence (http://creativecommons.org/licenses/by/4.0/), which permits unrestricted re-use, distribution, and reproduction in any medium, provided the original work is properly cited.

doi:10.1017/S0959774320000116 Received 23 Oct 2019; Accepted 23 Mar 2020; Revised 13 Mar 2020 
A general theme in assemblage theory emphasizes the vibrant and active character of graves, which resonates well with the interest in ontology and materiality that has emerged in the humanities and social sciences in the new millennium (Harris \& Cipolla 2017). So far, research has been occupied with the general theoretical and philosophical foundations of assemblages. In order to become a viable tool for burial analysis, however, there is also a need to explore methodological issues further; in other words, to examine how we can successfully apply such a perspective. In the following section, I begin by evaluating the potential of assemblage theory in burial archaeology in general, and continue by pursuing its potential application to cremation burials in particular.

\section{Becoming assemblages}

In the aftermath of the heyday of interpretative philosophies, some archaeologists have begun to explore what has been termed assemblage theory (Fowler 2013; Hamilakis \& Jones 2017; Jervis 2019; Lucas 2012; Normark 2006). The source of inspiration is primarily found in the works of Gilles Deleuze and Felix Guattari (1987), but also in contemporary works of philosophy from authors such as Manuel DeLanda (2016), Karen Barad (2007) and Jane Bennett (2010). Deleuze and Guattari (1987, 253-60) employed the concept of assemblage to connote a more open and continuous type of arrangement in which certain elements come together. An assemblage is a temporary aggregation that is in constant flux because of territorializing (aggregating) and de-territorializing (disintegration) processes $(1987,98)$. Assemblages of this type are thus quite different from the conventional definition of collections of artefacts or aggregates deposited together. In a Deleuzian assemblage, some materialities may be functionally related, others may presuppose one another, and it can expand through a range of additive processes (Robb 2004, 134). John Law $(2004,42)$ defined assemblages as 'a process of bundling, of assembling, or better of recursive self-assembling in which the elements put together are not fixed in shape, do not belong to a larger pre-given list but are constructed at least in part as they are entangled together'. The main point of assemblage theory is thus not to define the boundaries of what appears as a totality, but to stress how assemblages emerge, gather and become through relations between humans and non-humans. To approach graves as assemblages is to recognize their fluid boundaries and the continuous processes of change. As Ben Jervis $(2019,49)$ put it,
We can view this assemblage [the grave] as a stratum, a collection of territorialised entities, cemented through the process of burial, although gradually overtaken by the materiality of the objects and materials which continue to decay long after the burial has been forgotten.

Each burial is thus a unique assemblage, 'constituted out of bundles of practices, materials, forms, and places that are becoming' (Fowler 2013, 221).

In his 2013 book on Early Bronze Age mortuary practices, Fowler stressed this processual character of burials by mapping the lines of becoming; that is, how burials continuously emerge through a wide range of territorializing and de-territorializing processes (Fig. 1). In assemblage theory, there is no absolute point of origin for any event or object and all actants contribute to shape assemblages in the present (Fowler 2013, 58). The dynamics of the assemblage relate not only to the various stages of decomposition of the interments in the grave, but also the apparatus (tools, models, concepts, etc.) employed in excavation and documentation, which aggregate in temporal (not merely sentient) bundles of relations. Ultimately, the individual excavators and later researchers of the present also become actants in the burial assemblage.

Assemblage theory thus involves a shift of focus from essentialism (the grave as an object) to becoming (the grave as a process). For Deleuze, becoming denoted instances of actualization; that is, 'entities and states of affairs coming into being when a set of virtual conditions actually get expressed in a specific way' (Holland 2013, 19). Such actualizations may include a badger digging into a burial or an archaeological excavation of the same feature. The main idea is that nothing necessarily exists prior to action, but that through action things 'emerge in the present through a particular set of relations' (Fowler \& Harris 2015, 132; Jervis 2019, 62). Without getting bogged down in philosophical deliberations, we might say that the world in assemblage theory is understood as a series of intra-actions of mutually constitutive agencies of humans and nonhumans (Barad 2007).

Assemblage theory can in many respects be seen as an 'archaeology of flux' that stresses exchangeability and multi-functionality, and where nothing has a fixed beginning or end but is always circulating, transforming and evolving. The obvious question is how one should go about studying such an unstable and changing world. In archaeology, assemblage theory has foremost been employed to study change on multiple scales and dissolve dualisms and culture-historical generalizations. For 


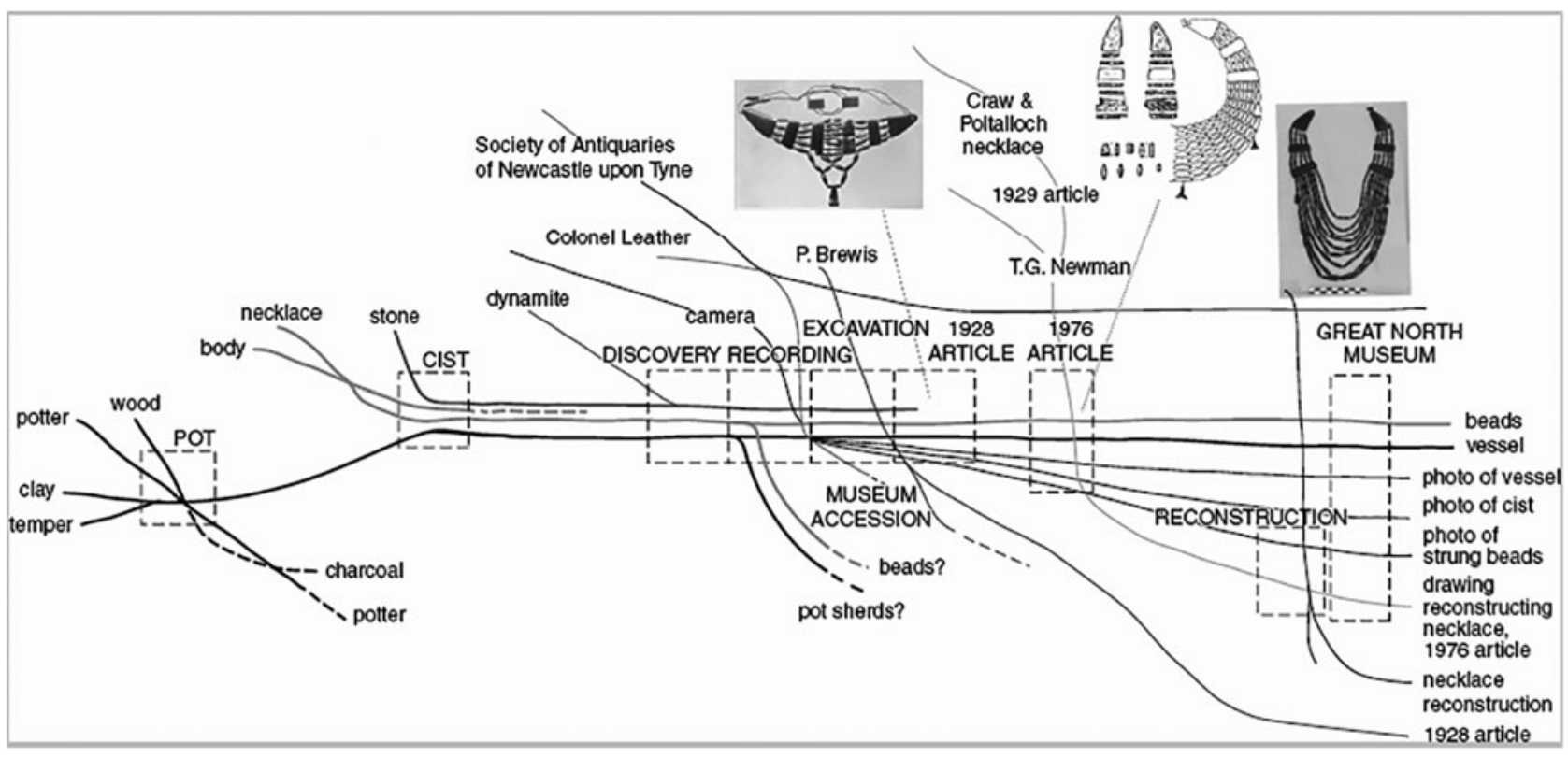

Figure 1. The lines of becoming of the Kyloe burial. (Reproduced with permission from Fowler 2013, 47.)

example, Jones and Sibbesson (2013) approached the Mesolithic-Neolithic transition as a series of overlapping transitions in human and non-human relations rather than a dual set of subsistence strategies and mentalities. In their 'Deleuzian version' of Stonehenge, Harris and Crellin (2018) employed assemblage theory to trace how the monument becomes, over time, through different materials and practices (see also Harris 2014). Crellin (2017) has also studied change in burial practices on the Isle of Man through different scales and tempos. In these examples, becoming is not only viewed in terms of human agency and practice, but as relational processes that also involve animals and materialities. Others have put greater emphasis on how archaeological features continue to become in the present. A good portion of Fowler's (2013) grave assemblage work concerned how the assemblage expands through excavation, documentation and research, of which he himself became a part (Fig. 1). This resonates with more general arguments that we shape and compose the assemblages we excavate, rather than unearthing something essential from the past (see Lucas 2012, 167). This argument, however, is only partly true and although assemblage theory is a viable way to study processes and change, there is a need for caution. The emphasis on fluidity and flux can lead to a type of ontological relativism, with every assemblage 'becoming everything, amounting to nothing' (Dewsbury 2011, 149; see also Fahlander 2017).
Indeed, new actants in a relational assemblage do not necessarily significantly alter its configuration; they only have the potential to do so. For example, a broken piece of machinery can be fixed by replacing parts with similar (but not the same) components without altering how the machine works. New methods and analyses can certainly increase the quality and level of information, but only rarely does the presence of a new archaeologist significantly alter the grave as an assemblage. The measuring apparatus will always affect the object of study to some extent, but excavating a grave is not on the same scale as studying phenomena at the atomic level (see Barad 2007). After all, although a grave undergoes changes over time, it is still recognized as a burial when it is excavated thousands of years after its construction. For instance, the pot in Fowler's example (Fig. 1) emerges from old sediments, the collection of materials and the processing of the clay and temper into a pot. Although it changes slowly over time, depending on circumstances and life course, it nevertheless has similar pot-qualities for quite a number of years. It is this particular form that is put into the grave, and not just any lump of clay.

A key issue in transforming the philosophical concept of assemblage into a viable archaeological method is thus to differentiate between the speed and impact of different processes and specify the extent of significant alterations. Although the world may be in a constant state of becoming, assemblages can also be tenacious and recalcitrant, since change 
occurs at different speeds and magnitudes. Some processes are extremely slow in relation to others, and the 'gradients of durability' of different materials vary greatly (Law \& Mol 1995, 279-80). To deal with the varying intensity of processes, the concept of 'phase transition', articulated by DeLanda (2016, 117), also proves helpful in illustrating how assemblages can undergo abrupt changes due to seemingly small and insignificant processes that, over time, reach critical points (Crellin 2017, 119; Harris 2014; Jervis 2019, 66).

That said, there may certainly be much to gather from tracing formation processes to identify the relations of becoming in terms of object itineraries (Jervis 2019, 79; Joyce \& Gillespie 2015). A seemingly ordinary grave urn may not necessarily be interchangeable with another. Similar types of pots may differ in terms of the origin of the clay and temper, what the pot has been used for and the relations in which it has been partaking. Take, for example, the Blasthill chambered tomb, which was partly built of boulders that were transported to the site, despite the fact that similar stone with similar functional properties was available locally (Cummings 2012). A similar example concerns Sufi prayer beads, or tasbihs, supposedly made of a particular soil from Karbala, where Muhammad's grandson shed his blood. When crafting the beads, the maker claims to be able to smell if the correct soil has been used (Saramifar 2017, 48). There is much to gain by mapping the lines of becoming, but formation processes, origins and the itineraries of objects and features can nonetheless be addressed without involving Deleuzian philosophy.

\section{Immaterial aspects of burial assemblages}

Applications of assemblage theory are firmly situated in a realist ontology, emphasizing the tangible and material. Despite this, some archaeologists wish to include immaterial aspects such as concepts, thoughts and conceptualizations in the assemblage. Deleuze and Guattari generally distinguished between 'mechanic assemblages' and the 'collective assemblage of enunciation', with the latter including discourse and semiotic signs (Deleuze \& Guattari 1987, 88; Wise 2011, 94). Karen Barad (2007, 334) also stressed the importance of waves and particles as concepts in physics. Indeed, anthropological concepts such as chiefdoms are central to archaeological interpretation, and steer and shape our thinking in a similar way to material actants (Fowler 2013, 68, 106; Lucas 2012, 253-4). Hence, some archaeologists have emphasized that immaterial concepts relating to death-such as individual and eschatological beliefs-are parts of the assemblage (Crellin 2017, 115; see also Harris 2017, 129; 2018, 89). Hamilakis $(2017,172)$ equally recognized that co-functioning entities often involve seemingly immaterial components that require materiality to be enacted (e.g. discourses, memories and affects, not just linguistic utterances and signs).

Although our ideas about graves affect the way a burial is actualized through excavation and interpretation, the materiality of the assemblage also offers resistance. We do not simply apply our ontology to the world. Our engagement with the world generates perspectives, theories and epistemologies, including ideas of nature as separated from culture and material from immaterial phenomena (Bruun Jensen et al. 2016, 154). It may thus be inadvisable to equate ideas, thoughts and concepts taking place within the mind with material actants. This does not mean that they are insignificant, but quite the opposite: concepts and ideas are integrated parts of the world rather than things that hover above it. They are not conceived in the heads of people, but emerge from a need to conceptualize real phenomena when engaging with the world. Sensual affects are real, but the things we associate them with (memories, metaphors, etc.) are not-they are relational effects of engagements with the world. After all, 'belief happens in and through things and what people do with them' (Morgan 2005, 8). That said, concepts and conceptualizations emerging from real relations may indeed have an impact on subsequent situations and follow their own lines of becoming. They are not primary actants, but owe their potential to make a difference to tradition and semantic effects. Thus, concepts such as particles and waves are not detached from reality: they had different trajectories of becoming, and different uses, before they were employed to describe what light is, just as in the example of clay, temper and the pot in Fowler's example (see Barad 2007, 334).

It can be argued that a funeral pyre not only becomes through fire, but is 'ignited' by acts derived from the beliefs and aims of the people who not only enact but also actualize the cremation. The practice of building a cremation pyre or assembling a grave may indeed rest upon concepts and ideas of death, the afterlife and the proper handling of a dead body. However, a particular eschatology can also be conceived as a result of relations between animacies and vibrant qualities of humans and non-humans (Ingold 2006; Jones 2012). Dead bodies are not walking about like living humans, but are nonetheless full of agency: their stomachs swell, their bodies change 
colour, begin to smell, leak substances and attract insects (Roach 2004). Thus, because dead bodies 'request' attention, they tend to 'attract' practices and materialities which often end up as a burial assemblage. In a similar sense, ideas of the afterlife may thus partly be a result of the vibrancy of dead bodies. Concepts and ideas may be based on reality, but since realities are not necessarily the same as the concepts and ideas based upon them, it is important to be observant of their effects. They are indeed part of our measuring apparatus and involved in how an assemblage enfolds, but as argued above they are mutually constituted, and their effects may not always be significant. This flexibility and the fluid character of concepts and ideas are crucial to understanding potential alterity in the past. Holbraad has argued that, in order to grasp the alterity of the ethnographically other, we should worry less about 'how far natives might (or should) be considered as humans, agents, subjects and so on, we should be asking what concepts of humanity, agency, subjectivity and more our anthropological engagement with them might yield, and be fully prepared to be surprised by what we find' (Holbraad 2011, 17, emphasis original). In a similar way, a central objective for burial analyses would be to explore how concepts such as death, burial and the afterlife in different times and places are articulated through human and more-than-human relations, and be 'fully prepared to be surprised by what we find'.

\section{Generative aspects of burial assemblages}

Thus far, assemblage theory in archaeology has to a large extent focused on the becoming of assemblages-what they are and what they are not. There is less discussion about what assemblages do. In Deleuze and Guattari's framework, assemblages are 'compositions that act', as hinted at by their choice of the French term agencement (Wise 2011, 91). The term connotes both fitting together and the transformative potential of 'doing undergoing' (Dewsbury 2011, 150; Ingold 2017, 9). It is probably too simple to discuss grave assemblages in terms of territorializing and de-territorializing processes alone. There is a wide range of generative aspects encapsulated in both the visual and sensory aspects, as well as the more intricate ways in which some assemblages are configured to work with a specific aim in mind. It should be noted that agency, in this case, is a relational effect and not a quality of humans and non-humans. It is thus not a question of whether assemblages 'have' agency or not, but in what ways they have potential to incite or affect certain processes. It is important to note, however, that a focus on relations does not mean that the properties and qualities of things and matter are unimportant or interchangeable.

The potential generative aspect is a promising motivation for applying assemblage theory in burial studies. To be meaningful, however, it needs to involve something more than the sum of the properties of its parts. A modern car, for example, becomes something more as an assemblage than it would from the individual parts. As assemblages, vehicles such as cars tend to develop individual properties in relation to humans and non-humans and can even appear sentient when they behave in certain unpredicted ways (Bryant 2014, 52). Burial assemblages can work in this way too: for example, Lucas (2012) emphasized how assemblages tend to gather and attract, and burials often work in precisely that way as centres of gravity, accumulating stuff by drawing attention and provoking responses (see van Vliet 2015, 44). The individual parts of burial assemblages (interments, bodies, superstructures, etc.) can also work together in different ways. While from an ontological point of view they do not have the mechanical properties of machines, they may still be carefully assembled with the aim of affecting the world. Jane Bennett, who discussed the agential aspects of assemblages in particular, argued that 'an assemblage owes its agentic capacity to the vitality of the materialities that constitute it' $(2010,34)$. Based on the material vitalism of Deleuze and Guattari $(1987,411)$, she emphasizes that matter is seldom inert, but vibrant. The lively (not necessarily living) and phenomenal qualities of materialities both 'do' things and 'make' others do things. For example, different materials often display a certain animacy (e.g. motion or affective agencies). Shiny surfaces or contrasting colours catch the eyes of both humans and non-humans, while other materials have the ability to blend with the background and become invisible (Conneller 2011). Stone is durable and able to uphold structures for very long periods of time, while wood and other biological materials disintegrate at a faster rate. These properties of materials and materialities, including origins and itineraries, are potentially vital properties in the construction of burial assemblages. For instance, the use of stone lining not only physically delimits a grave assemblage, but also anchors it in time because of the enduring and heavy qualities of stone. Other de-territorializing processes, such as disintegration, are sometimes sought after: for example, to separate the bones of a body from the soft tissue, which has proved ontologically important in 
inhumation and air burials. It is also conceivable that processes of disintegration are utilized to merge different materials, such as red ochre and bone, or even two different bodies (Fahlander 2013). Such practices are not necessarily dependent on magical or animist ontologies, but are based on the real, agentive and affectual properties of materials that can be manipulated and combined in various ways.

This type of aggregation of matter compiled to intra-act is a common feature in many small-scale societies, both historically and in the present (Astor-Aguilera 2010; Jelicic n.d.; Preston Blier 1995; Zedeño 2008). Small bags containing an assortment of bones, crystals, weeds, etc. are sometimes found in prehistoric burials or as depositions, with no apparent functional purpose (e.g. Brück 2004). As such they are often referred to as ritual or magic collections of materials endowed with meaning. One interesting example is the 'bundles' of the North American Plains groups, which are compiled of different artefacts, substances and qualities with the intention of affecting the world (Pauketat 2013, 41; Pauketat \& Alt 2018, 75; Zedeño 2008; see also Harris \& Crellin 2018). The bundles generally come in three types: personal, medical and ceremonial. The personal bundles reflect the owner's person and life-course, the medical are aimed at healing and the ceremonial are employed in communal rituals (Zedeño 2008, 364). Without advocating any direct analogy, the bundles illustrate a way of thinking that it may be fruitful to apply to burial assemblages: a personal grave-bundle is similar to the typical interpretation of graves as representing the dead; a medical bundle corresponds to a grave-bundle that aims to heal and aid the dead in the afterlife; and a ceremonial grave-bundle may aim to disarm the agency of the dead in the world of the living. A particularly interesting aspect of bundling is the idea that the different materialities can transmute into a new object or, in terms of a burial, a new entity (Zedeño 2008, 364-6; see Fahlander 2013; 2014; 2018a). Here is where ontology comes into play: what assemblages do may not always be measurable in scientific terms; rather, different ontologies allow them to be generative in different ways. To discuss the generative powers of assemblages is, however, not the same thing as advocating anthropocentric concepts of animism; the world included plenty of vibrancy and animacies prior to human understanding, and there is no need for 'an infusion of spirit into substance' (Ingold 2006, 10). The bundling of different materials can instead be understood in terms of a vitalist technology building on real circumstances and physical processes (Fahlander 2019). The 'power' of certain materialities or materials need not derive solely from culture-specific meanings, but from the qualities and agencies of the materials themselves. Materialities such as bone, metals, liquids and glimmering stone do things with or without the presence of humans. Some materialities may indeed be imbued with powers or agency because of their colour, shape, properties and itineraries, while others get their efficacy from relations, origins, contact, or similarity, as in sympathetic magic (Brück \& Jones 2018; Fahlander 2018b). To pick one example, during the Early Bronze Age in northern Europe, people began to bury the dead in hollowedout oak logs covered by large mounds. These logs have previously been viewed as appropriate coffins for the corpses, or perhaps seen as symbolic 'death boats'. A closer inspection, however, reveals that measures have been taken to retain a certain 'treeness' in the hollowed-out logs: some of them are roughly cut and crooked, full of knots, and sometimes the bark is left on, making them essentially hollowed-out trees (Fahlander 2018b). The practice of virtually burying the dead inside trees that were also 'planted' inside water-logged mounds can be interpreted as a way of utilizing the vibrant qualities and agencies of trees in order to manage the dead. The example also illustrates the relation between the inner grave (the $\log$ ) and the superstructure (a mound constructed to keep the interior waterlogged). This vitalist aspect of burial assemblages can be both intentional and unintentional, and their generative aspects might be termed ontological agency or animic agency. The point here is that they are not only believed to work as a vitalist device because of the affective and generative qualities of the matter involved, but because they actually do stuff. It may thus be more appropriate to discuss burials as ensembles of humans and more-than-humans rather than assemblages (see Simondon 2017). From such a perspective, burials are comprised of a variety of elements which are intended to work in concert via qualities and relations as a kind of 'ensemblage'.

\section{Discussion: cremations as vitalist devices}

It should be evident by now that assemblage theory is not a ready-made toolbox that can be applied in burial analysis. It does not present a straightforward method, but encourages us to view the world from a slightly different perspective, emphasizing generative relations between humans and non-humans. Deleuze's oeuvre is especially complex, and strives towards the indeterminate rather than the definite. 
In order for the argument to become operative modifications are necessary, but without sacrificing its integrity. So far, assemblage theory has most prominently been characterized by attempts to develop an archaeological theory and method that has tangible consequences. Although processes of becoming have been discussed before in archaeology, assemblage theory puts greater emphasis on the potential meaning and generative effects of such processes: for instance, decay is not necessarily viewed as a purely neutral process, but is sometimes sought after and manipulated. As previously argued, the problem is how to manage the archaeologically relevant (i.e., interesting) relations without getting lost in ever-expanding Deleuzian assemblages. One viable approach is to follow the methods of actor-network theory (ANT) and focus on the active 'actants' or 'mediators' that actually do something, regardless of traditional classification or distance in space. In ANT, any humans or non-humans can, during certain relations, transform from passive intermediaries to full-blown actors (Latour 2005, 81). To investigate the interplay between humans and non-humans, Latour suggested that we try to locate those places and instances where ontologies and ideologies are acted out (actualized): for example, he proposed that global capitalism as a virtual phenomenon could be studied in abandoned factories, IBM's main office, or at scrapyards with obsolete electronics in Africa $(2005,175)$. Contrary to Bentham's utopia of the all-seeing panopticon from which everything can be observed simultaneously, Latour argued that such sites are oligopticons: sites from which one can get a 'sturdy but extremely narrow view' (2005, 181). They do not reveal all facets of a phenomenon, but are sites where ideologies and conceptions are actualized in and through the intra-action of real humans and materialities $(2005,188)$. On a smaller scale, cremation pyres and burials can be conceived as oligopticons in which the realities and the ideas of life and death are actualized. In the following, I illustrate how such an approach can be operationalized, and how both features can be understood as vitalist amalgamations of matter compiled to work in concert.

\section{Vitalist aspects of the pyre}

The cremation pyre is generally conceived as a type of assemblage comprised of practical parts (i.e. wood) and appropriate substances and materialities accompanying the dead body. The variability here is great, but not infinite, mainly because the pyre has to work to cremate a human body successfully to ashes and bones (Thompson 2015). Although there is a broad range of studies of cremations, most tend to focus on the ability of fire to consume and transform the dead body into another state or material form (Williams et al. 2017, 15). The agencies of fire, however, are not restricted to vaporizing materials only; they also create heat, flames, smoke, sound and light (Moskal-del Hoyo 2012, 3390). Moreover, fire also has the power to melt and merge different materials (Sørensen \& Bille 2008). These are perfectly real processes that can potentially play a significant part in why a dead body is cremated in a particular way along with certain materialities and substances.

Interestingly, there are several indications that some cremation pyres were assembled so as not merely to consume a corpse, but to utilize other agencies of fire. The sometimes large numbers of animals placed on the pyre demand special care if the cremation is to be successful (Bond 1996; Fig. 2). It is not enough to dismiss these additional bodies as mere offerings; they may certainly have symbolic connotations, but it would be reductive not to explore other potential reasons why a cremation pyre is configured in a particular way. After all, real bodies with tangible properties are put on the pyre, not symbolic representations. For example, just as tin and copper fuse into bronze, a similar ability of fire can be utilized to merge different bodies and parts of bodies on the pyre into a hybrid entity as a way of disarming or enhancing the potential agencies of the dead (see Fahlander 2013). Moreover, although they are composite technical constructions, pyres are not always built only to be functional. In a study on cremations in Roman Gaul, for example, Deforce and Haneca (2011) demonstrated a selection process for wood for the pyre. They were able to establish that the pyres contained many different types of wood, some of which were non-local (see also Marston 2009; Moskal-del Hoyo 2012). They also found that the cremations, in comparison to household fires, included a significantly higher number of different tree species. This indicates that the selection of different types of wood for the pyre did not rely on functional and practical aspects alone. The selection may, of course, have been based on symbolic connotations and origins, but might also have involved tangible sensory aspects such as sound and smell (see Fahlander 2014; Hamilakis 2017). Viewing the whole pyre as comprising a carefully amalgamated contraption thus emphasizes the more potentially generative relations between bodies, materials and materialities affected by the agencies of fire. 


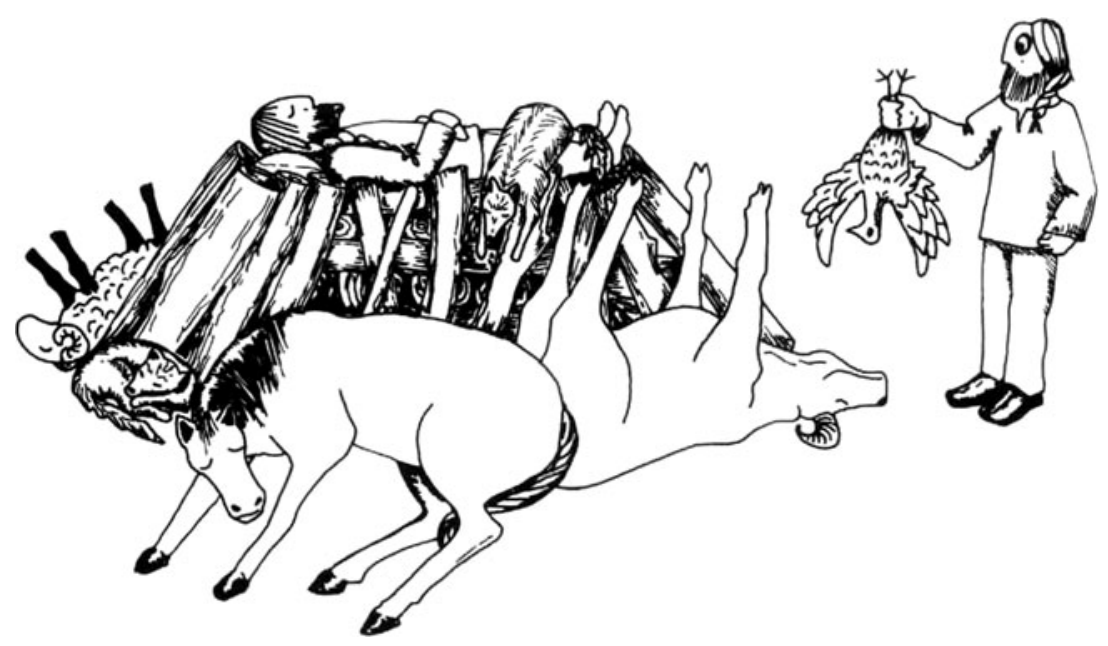

Figure 2. Illustration of a common envisioning of an Anglo-Saxon cremation (left) and what it actually would have looked like taking into consideration the remaining animal bone (right). (Reproduced with permission from Bond 1996, 80.)
Vitalist aspects of the grave

A grave that mainly comprises remains from the cremation is only rarely a direct consequence of the pyre assemblage. In some instances, the remains of the pyre are covered by a cairn or a mound; more frequently, parts of the pyre are collected and gathered in a pit at another location with or without a 'wrapping' and superstructure (Harvig et al. 2014). This step entails a process of choosing which remains from the pyre to bury, how to bury them, and where. In archaeology, the sorting practice is generally understood to be centred on ideas of the body and the dead person (Brück 2004, 324; Jennbert 2004, 192). There are, however, indications that cremation graves can be more complex assemblages with other aims and functions. For instance, the amount of human bone in cremation graves is less than that which would be expected to remain from a cremated individual (cf. Harvig \& Lynnerup 2013), and there is a bias as to which bones are selected and placed in the grave. In Swedish Iron Age cremations, for example, parts of femurs, humeri, ribs and skulls are generally overrepresented (Jennbert 2004, 192). In general, Late Iron Age urns may also contain substantial amounts of animal bones mixed with the human bones. These additions are generally viewed as personal pets, food offerings, or a particularly symbolic species that has been put on the pyre (Bennett 1987; Williams 2005). It is, however, compelling that many cremations contain more animal than human bone, and a few graves lack human bones altogether (Bond 1996, 78; Sigvallius 1994, 62). Moreover, the degree of combustion between bones varies, and unburnt material is sometimes also added (Sigvallius 1994, 128f). Although this has been interpreted as remains from a second stage in the funerary ritual involving meals shared between the dead and the living (Groot 2008, 188 ), many of these animal parts were not normally consumed as food (Sigvallius 1994, 134). The urns may also hold plenty of other unburned materials, such as seeds, stones, hazelnuts, fossils, plant remains, avian eggshells, minerals and various metal objects (e.g. Gräslund 1980, 54; Jelicic n. d.). It is difficult to deny that there would have been a reason for carrying out such elaborate practices of assembling different materials and substances in a burial urn.

It is important not to focus on the content of the cremated remains alone, but to also consider their wrapping: the urn, box, cloth, etc., as well as the superstructure and its relation to the physical environment. If the burial indeed is compiled as a generative amalgamation, these factors are most probably related, as in the previously mentioned example of the Bronze Age mounds. This does not exclude the idea that superstructures are also burial markers; it merely acknowledges that they may have other functions. For example, during the early part of the early Scandinavian Iron Age, burials contained almost exclusively cremated human bone covered by carefully designed superstructures of selected stones in a variety of forms (Fig. 3). In the latter part of the period, this relation changes: the burials are more varied and contain many more materialities besides the cremated bone, not all of which are taken from the pyre. Correspondingly, the superstructures are more uniform, and generally consist of a soil-filled heap of stones with or without a kerb (Bennett 1987, 20). Comparisons of the type of superstructure and status, gender or age of the buried individuals rarely show any significant relations between the different Early Iron Age graves. The often elaborate and carefully 
Figure 3. Examples of Scandinavian burial superstructures from the Early Iron Age. (Photograph: Per Gustafsson, (C) Antiquarian-Topographical Archive (ATA); reproduced with permission.)

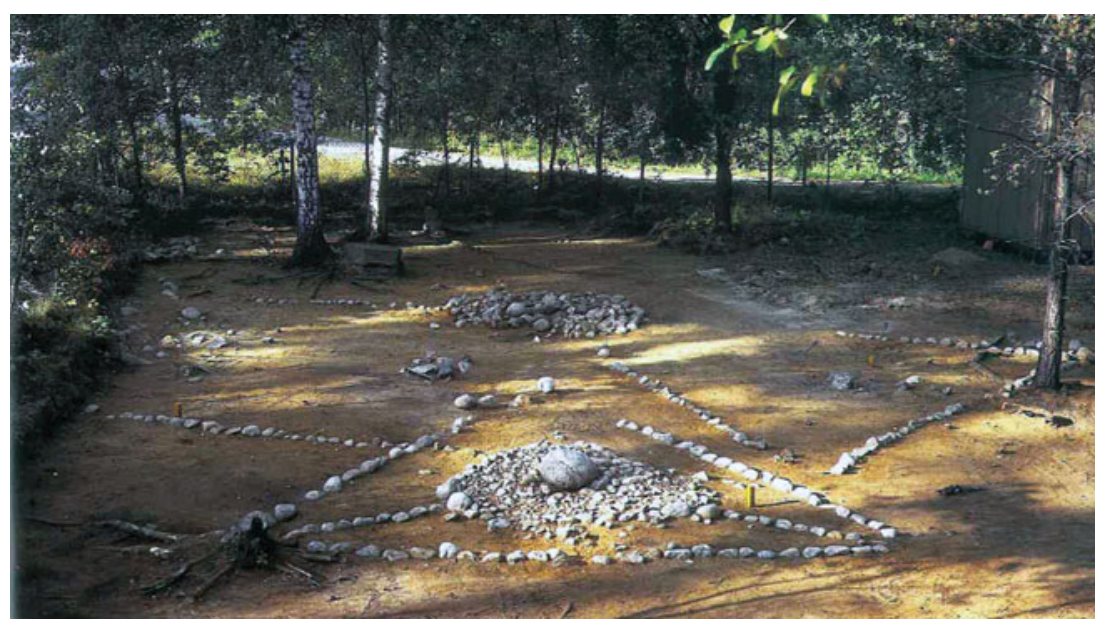

made nature of the superstructures is a strong indication that they have functions other than as memorial monuments covering dead individuals.

\section{Sjonhem 12/56: a Bronze Age burial assemblage on Gotland}

The above-discussed instances of selecting, gathering, producing, altering and arranging different substances and materialities suggest that cremation graves to a certain extent can be conceived as a type of vitalist amalgamation-that is, a composite device assembled to do something, whether that something is potentially to enhance or disable the agencies of the dead, or manage unruly materialities such as cremated bone. Prehistoric cremations are varied in composition, and no single example encompasses the full range of the qualities and agencies of the pyre and the grave discussed above. As a specific illustration of the argument, however, a brief example of a Bronze Age cremation burial will serve to emphasize the potential of such an approach. On the Swedish island of Gotland, an intriguing cremation burial (Sjonhem $1: 1$, grave 12/56) was excavated in the 1950s by Erik Nylén (1958). Before excavation, the grave appeared to be a typical round burial mound, $12 \mathrm{~m}$ in diameter and one metre high. When the mound of soil mixed stone was removed, a series of five concentric stone circles emerged (Fig. 4b). The circles seem carefully laid out, but are somewhat asymmetrical in terms of the size of the stones and the space between the circles. The larger stones in the southern part become gradually smaller towards the north. Another interesting detail is the odd pointed stone in the first circle that 'connects' with the innermost circle, which is incomplete. In the centre of the feature, a $1300 \mathrm{~g}$ layer of cremated bones, 19 bronze fragments and few pieces of mica were deposited. The bones comprise the remains of two adults-possibly a man and a woman-mixed with a few animal bones from cattle and pigs, and were deposited without any 'wrapping'. Shards of at least two broken pots, however, were found among the stone circles, which could potentially have served as containers for holding and transporting the cremated bones. Underneath the layer of bones, bronzes and mica was an area of sooty soil.

No known cremation site can be linked to the grave, so the cremation phase of the assembly process can only be extrapolated through what remains within it. One such observation concerns a divergence in colour in the bones of the two adults, indicating that they were cremated separately (Gejvall in Nylén 1958, 36). The animal bones-a phalanx from a pig, and a cannon bone and tooth fragments from cattle or horses-are visually quite distinct from human bones, and would not have been selected from the pyre remains by mistake. Thus, whichever pyre these bones originate from, they have been intentionally added to the grave assemblage. The majority of the bronze fragments are partially melted and were probably part of at least one of the pyres, except for one spiral of bronze thread that has not been affected by heat.

\section{Becoming and assembling}

A rough time sequence in the construction of the monument can be ascertained stratigraphically. First, the innermost stone circle (and possibly the rest of the circles) was laid out. A sooty patch at the bottom of the cairn shows that a fire was lit over and partly outside this circle (Fig. 4a). Thereafter, the cremated remains were deposited 

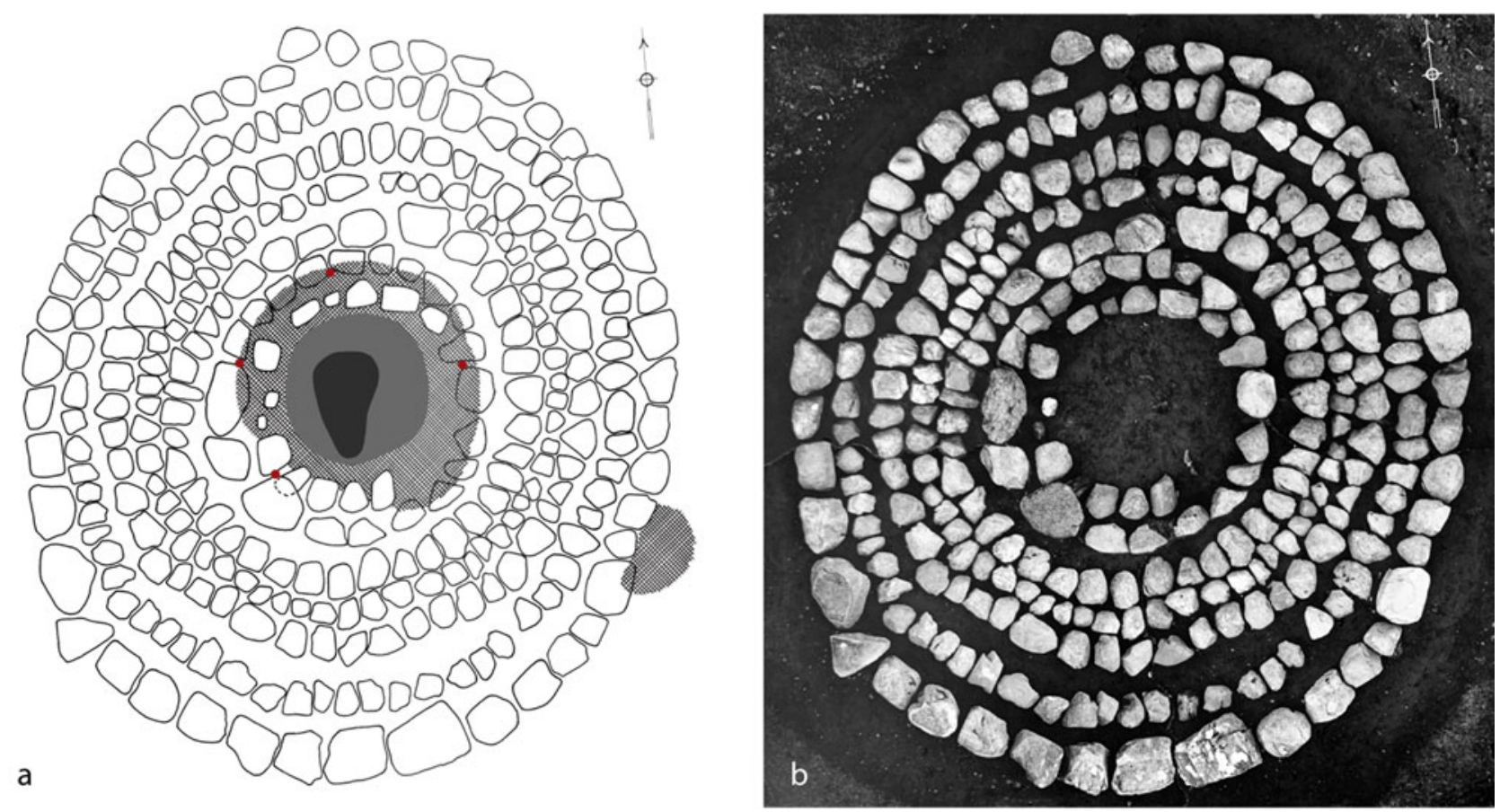

Figure 4. (a) Drawing of Sjonhem 12/56 with the underlying soot layer (hatched), layer of cremated bones (grey and black) and deposited concentrations of potsherds (red dots). (Modified from drawings by Einar Johansson.); (b) The concentric stone circles. (Photograph: Erik Nylén, (C) Antiquarian-Topographical Archive (ATA); reproduced with permission.)

together with the animal bones, bronzes and mica, and the whole feature was then covered by a mound of fire-cracked stone. To this, we must add at least two previous cremation pyres and the gathering (and possibly production) of the stones for the circles and cairn.

The sequence of events is interesting for both ritual analysis and for mapping the 'lines of becoming'. According to the excavators, the whole feature was covered by a mound close to the time of its construction, suggesting that the intricate stone circles had functions other than being primarily decorative or signifying status (Nylén 1958, 28). This also means, however, that the feature's lines of becoming are restricted to the construction phase. Due to issues surrounding excavation and documentation, information on the finds is limited and offers few means to explore the possible affective relations and itineraries of the two individuals, the animal bones, pots and bronzes in the grave (see Jervis 2019, 49-50); thus I will focus the following discussion to the real qualities, affordances and potential agencies.

The human bones are the focal point of the assemblage, and it is safe to assume the feature was constructed to care for, control, or maintain them. Although we do not know much about the two as individuals, it is significant that their bones are mixed and not buried in separate 'wrappings', as this suggests that identity and personality were not primary issues in this particular grave. The animal bones could potentially be 'replacements' for missing human counterparts, or reinforce the assemblage by adding powers stemming from their original agencies and functions; the teeth could, for instance, allude to transformative or fragmenting powers and the cannon and phalanx bones to movement. There may also be symbolic aspects associated with certain bones: in later Viking and Medieval periods, for instance, single cattle teeth are often found in Christian graves as apotropaic devices (Fahlander 2018c, 58; Gilchrist 2019, 141).

Mica, a particularly vibrant material, was deliberately added to the layer of bones. Besides its glimmering appearance, mica can withstand high temperatures, and some types can polarize light. It is frequently employed in traditional medicine to treat diseases of the respiratory and digestive tracts, as well as for rejuvenation of the skin. Scientific studies indicate that, properly processed, ground mica indeed has hypoglycaemic, hepatoprotective, anthelmintic and antimicrobial properties (Wijenayake et al. 2014). Although it is not evident if mica was added to 
the cremated bones because of these capacities, its real and vibrant qualities ought to have been considered generative to some extent.

The bronze fragments are also 'lively' in ways that go beyond the metal's shiny appearance. Bronze itself is an assemblage of copper and tin (neither of which are available locally), and it is a materiality forged by fire, but here also fragmented and deformed by fire. Among the pieces are a few fragments recognizable as a twisted ribbon torc. In Celtic culture, such items were worn by high-status individuals of both sexes, and were commonly associated with supernatural powers and deities. They were believed to be apotropaic, and were worn in battle as protective devices (Harding 2007, 270), suggesting that the pieces of torc were collected from the pyre and deposited among the cremated remains in the grave as protective actants.

In contrast, the 40 yellowish potsherds are rather anonymous. They originate from at least two pots, one with a straight rim, the other slightly curved. Unfortunately, there is no way to determine if these pots originally held the cremated bones or if this material was added of other reasons. The fact that they are deposited in small clusters in an intricate circular manner following the layout of the innermost stone circle (Fig. 4a), however, strengthens the interpretation that the mixing of bones was indeed intentional. Instead of being held in separate pots, the cremated remains were enclosed by a different type of ceramic 'wrapping' that in a way 'merged' the two individuals (and possibly also the animal bones, mica and bronze fragments).

Finally, the superstructure covering the construction may also have more than one function. It is significant that the cairn was made of fire-cracked stone, in contrast to the 'raw' stone used for the circles. Because fire-cracked stone must be produced, it is likely to differ in terms of qualities and agencies. Traditionally, fire-cracked stones have been assumed to be the unintended by-product of cooking pits; at other sites, however, the cracking of stone by fire is an intentional part of cremation graves (Bergström 2016). Fire-treated stone becomes fragmented, sooty, brittle and sharp-edged, and its interior is exposed. This treatment is thus not likely to be intended to enhance potential vitality, but rather the opposite. Regardless of the qualities that were considered important, the stones of the superstructure were apparently as carefully selected as those in the interior.

To these materials and materialities we must add fire and heat, which are key agents in this particular assemblage. Not only have the corpses been cremated, but also the metals, soil and stones of the cairn. Fire has been employed at least three times, potentially as a means to affect certain parts and/or make materials more compatible. In this particular case, fire fragments materials such as bone and stone as well as changing their colour. Fire also 'sterilizes' and cleanses the soil of vegetation where the cremated bones are deposited. Fire could also have been employed to separate spirit from matter, or release/evaporate qualities or agencies (i.e., stone), transforming corpses into a more persistent form (i.e. cremated bone).

\section{Adorn, protect, or bind?}

In traditional terms, the content of the cremated bone is 'durably sealed' due to the choice of material (stone) and form (labyrinth). In assemblage terminology, this can be expressed as 'entirely territorialized' and 'strongly coded' (DeLanda 2016, 22; Jervis 2019, 54) where 'change is denied' (Harris \& Crellin 2018, 68). There is a subtle difference in perspective here that may or may not be productive. From a vitalist perspective, there are several indications suggesting that the grave was a carefully constructed feature assembled to do something. Traditionally, the layout of graves tends to be understood as a visual spectacle to convey meaning during the funeral (e.g. Price 2010). This ocular view of graves is reinforced in the manner of making archaeological plan drawings and illustrations. From an assemblage point of view, however, the layout of a grave may also be 'functional' in a vitalist sense (see Brück \& Jones 2018).

Nylén (1958) originally suggested that the function of the stone circles was to 'bind the soul' of the dead to the grave. This fits well with the asymmetrical stone circles, partly arranged as a false labyrinth with no way out, but not with the added materialities in the centre. The torc, mica, animal bone and structured deposition of the potsherds suggest instead that they are placed there to protect and curate (although a combination is conceivable). Most importantly, the feature need not have been constructed to bind or assist a dead individual or a particular 'soul'; the carefully constructed assemblage may instead constitute a 'vault' intended to disarm and care for unruly materialities and/or non-transferable materialities such as personal inalienable possessions (the torc), or other unstable, potentially dangerous remains from the pyre (see Fahlander 2018c). Such an interpretation does not imply that the individual buried is of no importance, merely that the primary function of graves is not necessarily to be final resting places or 
memorials: they can also be vitalist devices compiled to handle particular materialities that need to be deposited in certain ways.

\section{Summary}

The recent attention to assemblage theory in archaeology runs parallel to a general interest in ontology and materiality and relational perspectives in the humanities and social sciences. Assemblage theory generally underscores the singularity of particular assemblages in a state of continuous becoming. It also stresses relations before essence, and to some extent ontology before epistemology, encouraging us to focus on what is rather than searching for hidden meanings. To emphasize how features become not only highlights origins and the flow of materials, but also what involved materialities do in their original form and place. In this text, the basic premises of assemblage theory and how it may contribute to burial archaeology have been evaluated. It is suggested that the focus on fluidity and processes of becoming runs the risk of being exaggerated, and that archaeological analyses need to balance the varying intensity and scope of territorializing (aggregation) and de-territorializing (disintegration) processes. Although the world is in a state of becoming, people nonetheless manage their daily encounters with different assemblages. The idea of including human concepts and conceptualizations in assemblages is also questioned. Immaterial aspects are indeed part of our apparatus, but it is difficult to distinguish between remnants of past interaction and what is incited by the material at hand. There is, of course, no objective and pre-conceptual way to study the past based on empirical evidence only, but the conflation of the material and the immaterial tends to nullify the symmetrical and nonanthropocentric facets of assemblage theory. Instead, putting greater emphasis on the generative and vibrant aspects of materialities and assemblages is suggested here. After all, many of our ideas and concepts are initiated, triggered and formed through our enactments with the world.

While some discussions of assemblage theory are quite complex and riddled with jargon, the perspective still suits archaeological studies well. We should, however, not expect that new theories will automatically provide radically new interpretations of the past. The most promising aspect of assemblage theory lies in its potential to gather new and more significant information from the material already at hand. An ontologically oriented outlook encourages us to consider what the materialities in the graves are supposed to do rather than their possible symbolic potential. It also stresses alternative classifications of materials and materialities that are different from the Linnaean and the Western scientific traditions. In this text, I have suggested that archaeological features such as cremation pyres and graves can be understood as carefully amalgamated 'ensemblages' made to be generative. This perspective does not presuppose an animist or magical ontology in the past, but is based on the tangible, vibrant and generative aspects of materials that include both humans and more-than-humans.

Assemblage theory thus can contribute not only by mapping the becoming of graves, but also by bridging the traditional divide between magic and reality through emphasizing the vitality and vibrancy of matter, and how these can become affective in relation to other materialities. It opens possibilities for an 'agnostic' and less anthropocentric discussion about how different aspects of a grave intra-act, and in which concepts of death and the afterlife are allowed to change. By keeping the focus on the tangible and real qualities of the involved materialities, excessive relativism or speculation can be reduced, while potentially different concepts such as identity, personhood, death and burial can be explored.

Fredrik Fahlander
Department of Archaeology and Classical Studies
Stockholm University
Lilla Frescativägen 7
SE-104 05 Stockholm
Sweden
Email: fredrik.fahlander@ark.su.se

References

Astor-Aguilera, M.A., 2010. The Maya World of Communicating Objects. Quadripartite crosses, trees, and stones. Albuquerque (NM): University of $\mathrm{New}$ Mexico Press.

Barad, K., 2007. Meeting the Universe Halfway. Quantum physics and the entanglement of matter. Durham (NC): Duke University Press.

Bennett, A., 1987. Graven - religiös och social symbol: strukturer i folkvandringstidens gravskick i Mälarområdet [The grave - a religious and social symbol: structural patterns during the Migration period in the Mälar area]. $\mathrm{PhD}$ thesis, Stockholm University.

Bennett, J., 2010. Vibrant Matter: A political ecology of things. Durham (NC): Duke University Press.

Bergström, P., 2016. Block och skärvig sten: en arkeologi av det abiotiska [Boulders and fire-cracked stone: an 
archaeology of the abiotic]. Unpublished master's thesis, Stockholm University.

Bond, J.M., 1996. Burnt offerings. Animal bone in Anglo-Saxon cremations. World Archaeology 28(1), 76-88.

Brück, J., 2004. Material metaphors: the relational construction of identity in Early Bronze Age burials in Ireland and Britain. Journal of Social Archaeology 4(3), 307-33.

Brück, J. \& A. Jones, 2018. Finding objects, making persons: fossils in British Early Bronze Age burials, in Relational Identities and Other-Than-Human Agency in Archaeology, eds E. Harrison-Buck \& J. Hendon. Louisville (CO): University of Colorado Press, 237-62.

Bruun Jensen, C., M. Ishii \& P. Swift, 2016. Attuning to the webs of en. Ontography, Japanese spirit worlds, and the 'tact' of Minakata Kumagusu. Hau: Journal of Ethnographic Theory 6(2), 149-72.

Bryant, L., 2014. Onto-cartography: An ontology of machines and media. Edinburgh: Edinburgh University Press.

Conneller, C., 2011. An Archaeology of Materials. London: Routledge.

Crellin, R.J., 2017. Changing assemblages. Vibrant matter in burial assemblages. Cambridge Archaeological Journal 27(1), 111-25.

Cummings, V., 2012. What lies beneath. Thinking about the qualities and essences of stone and wood in the chambered tomb architecture of Neolithic Britain and Ireland. Journal of Social Archaeology 12(1), 29-50.

Deforce, K. \& K. Haneca, 2011. Ashes to ashes. Fuelwood selection in Roman cremation rituals in northern Gaul. Journal of Archaeological Science 39(5), 1338-48.

DeLanda, M., 2016. Assemblage Theory. Edinburgh: Edinburgh University Press.

Deleuze, G. \& F. Guattari, 1987. A Thousand Plateaus. Capitalism and schizophrenia (trans. B. Massumi). Minneapolis (MN): University of Minnesota Press.

Dewsbury, J-D., 2011. The Deleuze-Guattarian assemblage: plastic habits. Area 43, 148-53.

Fahlander, F., 2013. Intersecting generations: burying the old in a Neolithic hunter-fisher community. Cambridge Archaeological Journal 23(2), 227-39.

Fahlander, F., 2014. Djur och människor: post-humanistiska perspektiv på yngre järnålderns gravar [Animals and men: post-human perspectives on Late Iron Age graves], in Med hjärta och hjärna: en vänbok till professor Elisabeth Arwill-Nordbladh[ With heart and mind: essays in honour of Professor Elisabeth Arwill-Nordbladh], eds. H. Alexandersson, A. Andreeff \& A. Bünz. Göteborg: Göteborgs Universitet, 237-50.

Fahlander, F., 2017. Ontology matters in archaeology and anthropology. People, things and posthumanism, in These 'Thin Partitions': Bridging the growing divide between cultural anthropology and archaeology, eds J. D. Englehardt \& I.A. Rieger. Boulder (CO): University Press of Colorado, 69-86.

Fahlander, F., 2018a. Nuances of what? Burials as relational configurations. Norwegian Archaeological Review 51(2), 78-81.
Fahlander, F., 2018b. The relational life of trees. Ontological aspects of 'tree-ness' in the Early Bronze Age of Northern Europe. Open Archaeology 4(1), 373-85.

Fahlander, F., 2018c. Grave encounters: ontological and material aspects of post-burial practices in south Scandinavian Late Iron Age. Primitive Tider 20, 51-63.

Fahlander, F., 2019. Petroglyphs as contraptions - animacy and vitalist technologies in a Bronze Age archipelago. Time and Mind 12(1/2), 109-20.

Fowler, C., 2013. The Emergent Past. A relational realist archaeology of Early Bronze Age mortuary practices. Oxford: Oxford University Press.

Fowler, C. \& O. Harris, 2015. Enduring relations: exploring a paradox on new materialism. Journal of Material Culture 20(2), 127-48.

Gardela, L. \& K. Kajkowski (eds), 2015. Limbs, Bones, and Reopened Graves in Past Societies. Bytów: Muzeum Zachodniokaszubskim w Bytowie.

Gilchrist, R., 2019. Sacred Heritage. Monastic archaeology, identities, beliefs. Cambridge: Cambridge University Press.

Gräslund, A-S., 1980. Birka IV. The Burial Customs. A study of the graves on Björkö. Stockholm: KVHAA.

Groot, M., 2008. Animals in Ritual and Economy in a Roman Frontier Community: Excavations in Tiel-Passewaaij. Amsterdam: Amsterdam University Press.

Hamilakis, Y., 2017. Sensorial assemblages. Affect, memory and temporality in assemblage thinking. Cambridge Archaeological Journal 27(1), 169-82.

Hamilakis, Y. \& A.M. Jones, 2017. Archaeology and assemblage. Cambridge Archaeological Journal 27(1), 77-84.

Harding, D.W., 2007. Archaeology of Celtic Art. London: Routledge.

Harris, O., 2014. Revealing our vibrant past: science, materiality and the Neolithic, in Early Farmers: The view from archaeology and science, eds A. Whittle \& P. Bickle. Oxford: Oxford University Press/British Academy, 327-45.

Harris, O., 2017. Assemblages and scale in archaeology. Cambridge Archaeological Journal 27(1), 127-39.

Harris, O., 2018. More than representation: multiscalar assemblages and the Deleuzian challenge to archaeology. History of the Human Sciences 31(3), 83-104.

Harris, O. \& C. Cipolla, 2017. Archaeological Theory in the New Millennium: Introducing current perspectives. Abingdon: Routledge.

Harris, O. \& R. Crellin, 2018. Assembling new ontologies from old materials: towards multiplicity, in Rethinking Relations and Animism: Personhood and materiality, eds. M. Astor-Aguilera \& G. Harvey. London: Routledge, 55-74.

Harvig, L. \& N. Lynnerup, 2013. On the volume of cremated remains - a comparative study of archaeologically recovered cremated bone volume as measured manually and assessed by Computed Tomography and by Stereology. Journal of Archaeological Science 40, 2713-22. 
Harvig, L., M. Thagård Runge \& M. Borre Lundø, 2014. Typology and function of Late Bronze Age and Early Iron Age cremation graves - a micro-regional case study. Danish Journal of Archaeology 3(1), 3-18.

Holbraad, M., 2011. Can the Thing Speak? (Working Papers Series \#7). Open Anthropology Cooperative Press. http://openanthcoop.net/press/2011/01/12/can-the-thing-speak/

Holland, E., 2013. Deleuze and Guattari's A Thousand Plateaus. London: Continuum.

Huntington, R. \& P. Metcalf, 1991. Celebrations of Death: The anthropology of mortuary ritual. Cambridge: Cambridge University Press.

Ingold, T., 2006. Rethinking the animate, re-animating thought. Ethnos 71(1), 9-20.

Ingold, T., 2017. On human correspondence. Journal of the Royal Anthropological Institute 23(1), 9-27.

Jelicic, A., n.d. The Natural Choice. Reconsidering Natural Products in Viking Age Burial Space.

Jennbert, K., 2004. Människor och djur. Kroppsmetaforik och kosmologiska perspektiv [People and animals. Body metaphorics and cosmological perspectives], in Ordning mot kaos. Studier av nordisk förkristen kosmologi [Order against chaos. Studies of Nordic pre-Christian cosmology], eds. A. Andrén, K. Jennbert \& C. Raudvere. Lund: Nordic Academic Press, 183-217.

Jervis, B., 2019. Assemblage Thought and Archaeology. Abingdon: Routledge.

Jones, A.M., 2012. Prehistoric Materialities: Becoming material in prehistoric Britain and Ireland. Oxford: Oxford University Press.

Jones, A.M. \& E. Sibbesson, 2013. Archaeological complexity: materials, multiplicity, and the transitions to agriculture in Britain, in Archaeology After Interpretation: Returning materials to archaeological theory, eds. B. Alberti, A.M. Jones \& J. Pollard. Walnut Creek (CA): Left Coast Press, 151-72.

Joyce, R.A. \& S.D. Gillespie (eds), 2015. Things in Motion: Object itineraries in anthropological practice. Santa Fe (NM): School for Advanced Research Press.

Latour, B., 2005. Reassembling the Social: An introduction to actor-network-theory. Oxford: Oxford University Press.

Law, J., 2004. After Method. Mess in social science research. London: Routledge.

Law, J. \& A. Mol, 1995. Notes on materiality and sociality. Sociological Review 43, 274-94.

Lucas, G., 2012. Understanding the Archaeological Record. Cambridge: Cambridge University Press.

Marston, J.M., 2009. Modeling wood acquisition strategies from archaeological charcoal remains. Journal of Archaeological Science 36, 2192-200.

Morey, D.F., 2006. Burying key evidence: the social bond between dogs and people. Journal of Archaeological Science 33, 158-75.

Morgan, D., 2005. The Sacred Gaze: Religious visual culture in theory and practice. Berkeley (CA): University of California Press.
Moskal-del Hoyo, M., 2012. The use of wood in funerary pyres: random gathering or special selection of species? Case study of three necropolises from Poland. Journal of Archaeological Sciences 39(11), 3386-95.

Normark, J., 2006. The Roads In-Between: Causeways and Polyagentive Networks at Ichmul and Yo'okop, Cochuah Region, Mexico. PhD thesis, Göteborg University.

Nylén, E., 1958. Pryda, Skydda, Binda? Om gravskickets mening och skärvstensrösenas problem. Med anledning av ett aktuellt bronsåldersfynd [Decorate, Protect, Bind? On the meaning of burial practices and the problem with heaps of fire-cracked stone. Concerning a recent Bronze Age find]. Gotländskt Arkiv 1958, 23-38.

Pauketat, T., 2013. An Archaeology of the Cosmos. Rethinking agency and religion in Ancient America. London: Routledge.

Pauketat, T. \& S. Alt, 2018. Water and shells in bodies and pots. Mississippian rhizome, Cahokian poiesis, in Relational Identities and Other-than-Human Agency in Archaeology, eds E. Harrison-Buck \& J. Hendon. Louisville (CO): University Press of Colorado, 72-99.

Preston Blier, S., 1995. Vodun. West African roots of vodou, in Sacred Arts of Haitian Vodou, ed. D. Cosentino. Los Angeles (CA): UCLA Fowler Museum of Cultural History, 61-87.

Price, K., 2010. Passing into poetry: Viking-Age mortuary drama and the origins of Norse mythology. Medieval Archaeology 54, 123-56.

Roach, M., 2004. Stiff: The curious lives of human cadavers. New York (NY): W.W. Norton.

Robb, J. 2004. Extended artefact and the monumental economy: a methodology for material agency, in Rethinking Materiality: The engagement of mind with the material world, eds E. DeMarrais, C. Gosden \& C. Renfrew. Cambridge: McDonald Institute for Archaeological Research, 131-9.

Saramifar, Y., 2017. Crafting sacrality from the tensile life of objects: learning about the material life of prayer beads from a Khaksari Sufi Murshid. Contemporary Islam 12(1), 39-55.

Sigvallius, B., 1994. Funeral Pyres: Iron Age Cremations in North Spånga. PhD thesis, Stockholm University.

Simondon, G., 2017. On the Mode of Existence of Technical Objects. Minneapolis (MN): Univocal.

Sørensen, T.F. \& M. Bille, 2008. Flames of transformation: the role of fire in cremation practices. World Archaeology 40(2), 253-67.

Thompson, T. (ed.), 2015. The Archaeology ofCremation: Burned human remains in funerary studies. Oxford: Oxbow.

van Vliet, K., 2015. In Line With Things: A Neomaterialist Approach to Archaeological Assemblages. Unpublished masters dissertation, Stockholm University.

Wijenayake, A., A. Pitawala, R. Bandara \& C. Abayasekara, 2014. The role of herbometallic preparations in traditional medicine - a review on mica drug processing 
and pharmaceutical applications. Journal of Ethnopharmacology 155(2), 1001-10.

Williams, H., 2005. Animals, ashes and ancestors, in Beyond Skin and Bones? New perspectives on human-animal relations in the historical past, ed. A. Pluskowski. (BAR International series S1410.) Oxford: British Archaeological Reports, 19-40.

Williams, H., J. Cerezo-Román \& A. Wessman, 2017. Introduction. Archaeologies of cremation, in Cremation and the Archaeology of Death, eds. J. Cerezo-Román, A. Wessman \& H. Williams. Oxford: Oxford University Press, 1-24.

Wise, J.M., 2011. Assemblage, in Gilles Deleuze. Key concepts, ed. C.J. Stivale. Durham: Acumen, 91-102.
Zedeño, M.N., 2008. Bundled worlds: the roles and interactions of complex objects from the North American Plains. Journal of Archaeological Method and Theory 15(4), 362-78.

\section{Author biography}

Fredrik Fahlander is associate professor of archaeology at Stockholm University. His research focuses on theory and methodology in general and materiality and ontology in particular. Current research concerns burial archaeology and Bronze Age rock art. 